\title{
Myocardial Extracellular Volume Quantification by Cardiovascular Magnetic Resonance and Computed Tomography
}

\author{
Paul R. Scully ${ }^{1,2} \cdot$ Gorka Bastarrika $^{3} \cdot$ James C. Moon ${ }^{1,2} \cdot$ Thomas A. Treibel $^{1,2}$ \\ Published online: 6 March 2018 \\ (C) The Author(s) 2018. This article is an open access publication
}

\begin{abstract}
Purpose of review This review article discusses the evolution of extracellular volume (ECV) quantification using both cardiovascular magnetic resonance (CMR) and computed tomography (CT).

Recent findings Visualizing diffuse myocardial fibrosis is challenging and until recently, was restricted to the domain of the pathologist. CMR and CT both use extravascular, extracellular contrast agents, permitting ECV measurement. The evidence base around ECV quantification by CMR is growing rapidly and just starting in CT. In conditions with high ECV (amyloid, oedema and fibrosis), this technique is already being used clinically and as a surrogate endpoint. Non-invasive diffuse fibrosis quantification is also generating new biological insights into key cardiac diseases.

Summary CMR and CT can estimate ECV and in turn diffuse myocardial fibrosis, obviating the need for invasive endomyocardial biopsy. CT is an attractive alternative to CMR particularly in those individuals with contraindications to the latter. Further studies are needed, particularly in CT.
\end{abstract}

Keywords Extracellular volume $\cdot$ Computed tomography $\cdot$ Cardiovascular magnetic resonance $\cdot$ Tissue characterization

$\begin{array}{ll}\text { Abbreviations } \\ \text { AS } & \text { Aortic stenosis } \\ \text { AR } & \text { Aortic regurgitation } \\ \text { CMR } & \text { Cardiovascular magnetic resonance } \\ \text { CT } & \text { Computed tomography } \\ \text { CVF } & \text { Collagen volume fraction }\end{array}$

This article is part of the Topical Collection on Cardiac PET, CT, and MRI

Thomas A. Treibel

thomas.treibel@bartshealth.nhs.uk

Paul R. Scully

paul.scully@bartshealth.nhs.uk

Gorka Bastarrika

bastarrika@unav.es

James C. Moon

james.moon@bartshealth.nhs.uk

1 Cardiac Imaging Department, Barts Heart Centre, St Bartholomew's Hospital, 2nd Floor, King George V Building, West Smithfield, London EC1A 7BE, UK

2 Institute of Cardiovascular Science, University College London, Gower Street, London WC1E 6BT, UK

3 Clínica Universidad de Navarra, University of Navarra, Avda/Pio XII 55, 31008 Pamplona, Spain

$\begin{array}{ll}\text { DCM } & \text { Dilated cardiomyopathy } \\ \text { ECM } & \text { Extracellular matrix } \\ \text { ECV } & \text { Extracellular volume } \\ \text { ECV }_{\mathrm{CMR}} & \begin{array}{l}\text { Extracellular volume quantified by cardiovascular } \\ \text { magnetic resonance }\end{array} \\ \text { ECV }_{\mathrm{CT}} & \begin{array}{l}\text { Extracellular volume quantified by computed } \\ \text { tomography }\end{array} \\ \mathrm{HCM} & \text { Hypertrophic cardiomyopathy } \\ \mathrm{HF} & \text { Heart Failure } \\ \mathrm{GBCAs} & \text { Gadolinium based contrast agents } \\ \text { IHD } & \text { Ischaemic heart disease } \\ \text { LGE } & \text { Late gadolinium enhancement } \\ \text { MI } & \text { Myocardial infarction } \\ \text { MR } & \text { Mitral regurgitation } \\ \text { SAP } & \text { Serum amyloid P component }\end{array}$

\section{Introduction}

Myocardial fibrosis is a frequently unwanted, common end point in the majority of pathological mechanisms affecting heart muscle. It can occur as focal scarring due to replacement fibrosis following myocyte death (apoptosis, autophagy or necrosis) or as diffuse fibrosis due to expansion of the collagen fibre network around individual myocytes or myocyte 
bundles [1]. The best non-invasive technique for visualising focal fibrosis is cardiovascular magnetic resonance (CMR) using late gadolinium enhancement (LGE), because of the high contrast, high spatial resolution and whole heart coverage. Although resultant image quality is currently reduced, myocardial fibrosis can also be assessed with cardiac computed tomography (CT) both use an extracellular, extravascular contrast agent that lingers in extracellular water in areas of scar, due to a higher volume of distribution and slower kinetics. Visualization of diffuse fibrosis until now has remained challenging and limited to the domain of the pathologist, who was able to measure the extracellular matrix (ECM) directly on histological sections using stains specific for connective tissue [2]. Coupled with this, no useful blood biomarkers of myocardial fibrosis are currently extant. In the last 7 years, the same contrast agents have begun to be used to measure diffuse interstitial expansion (as well as focal scar), by measuring the extracellular volume (ECV). This review will focus on the quantification of ECV using the two most commonly used contrast agents: gadolinium and iodine based.

\section{Development of an Extracellular Contrast Agent}

An extracellular contrast agent has a key set of properties: (1) homogeneous distribution; (2) high water, but no fat solubility; (3) not adsorbed, actively transported, protein-bound or metabolized; (4) non-toxic, stable and freely cleared from the body and (5) readily measurable. Iodine and gadolinium compounds both fulfil these requirements as contrast agents. They diffuse rapidly and passively from the vascular space into extracellular tissue, but not into the intracellular space-leading to the term 'extracellular, extravascular contrast agent'. Following an intravenous bolus, they enter the myocardium down a concentration gradient ('wash-in phase'), and later, while being cleared, they return to the blood pool down the reverse concentration gradient ('wash-out phase'). This occurs over seconds to minutes in healthy myocardium, but in scar tissue (focal or diffuse), these pharmacokinetics are delayed due to changes in coronary flow rates, capillary permeability, functional capillary density and the presence of a dense, hydrated collagen matrix [3]. In addition, the increased volume of extracellular water present in scar compared to normal myocardium means total accumulation is higher. The combined result is that, at a certain time 'late' after a bolus, there is more contrast agent in scar than in the blood or remote myocardium and measurable signal is therefore changed.

In CMR, gadolinium-based contrast agents (GBCAs) are used due to their unique magnetic properties (gadolinium is a paramagnetic metal with the most unpaired electrons) [4]. They are particularly efficient T1-relaxing agents, resulting in increased signal on T1-weighted images and typically appearing bright on a $\mathrm{T} 1$ inversion recovery image. The relaxation rate ( $\mathrm{R} 1$ or $1 / \mathrm{T} 1)$ is directly proportional to the concentration of gadolinium. In CT, non-ionic iodinated contrast agents have become the most commonly used contrast agents [4, 5]; they are water-soluble, extracellular, extravascular contrast agents, which are not metabolized and are excreted by the kidneys $[6,7]$. CT attenuation values (represented as Hounsfield units, HU) are directly proportional to the concentration of iodine.

\section{Extracellular Volume Imaging by CMR}

Until recently, the gold standard of diagnosing diffuse fibrosis was endomyocardial biopsy, which is invasive (carrying risk) and is prone to sampling errors. This has led to the development of new, non-invasive techniques to better quantify diffuse fibrosis. CMR allows non-invasive tissue characterization of the myocardium and as such, is being increasingly used to identify the aetiology of a range of cardiomyopathies. LGE is the mainstay of this myocardial characterization and allows the detection of focal fibrosis $[3,8]$. This technique combined with functional imaging is the main reason that CMR is so useful clinically. LGE imaging relies on the delayed postcontrast difference in $\mathrm{T} 1$ between areas of fibrosis (more gadolinium, shorter T1) and healthy myocardium (less gadolinium, longer T1) [9], making it ideal for identifying focal areas of fibrosis. In diffuse fibrosis, this relative difference is lost, so conventional LGE imaging struggles - being a difference test where the operator selects one 'normal' tissue to null making all other tissues 'bright' $[9,10 \bullet \cdot]$. GBCAs change tissue T1; however, the native (non-contrast) T1 also changes with pathology. Advances in CMR sequences now permit its quantification via T1 mapping, which offers absolute values of T1, rather than relative differences in signal intensity. [10••]

Native T1 describes the signal in the whole of the measured myocardium and therefore represents a composite signal from all species present - this signal is swamped by iron or gadolinium if present and in their absence is measuring the signal of both the cardiac myocytes and the ECM $[10 \bullet \cdot$. Therefore, fibrosis/oedema/amyloid and associated water increase T1, and conversely increased cellularity (athleticism), iron (thalassemia) or fat (Anderson Fabry disease) decrease T1 $[10 \bullet \cdot, 11 \bullet, 12 \bullet]$.

The use of extracellular GBCAs in CMR offers the opportunity to quantify the extracellular (i.e. interstitial) space, relative to the intracellular (i.e. myocyte) space, which is the essence of ECV quantification. It dichotomises the myocardium into myocytes and matrix. In conjunction with myocardial volume, ECV can be used to calculate the relative volumes of each compartment. It is expressed as a volume fraction and provides us with unique insights into the pathophysiology of a range of myocardial diseases [10••]. 
T1 mapping and ECV may provide an advantage over conventional LGE imaging, by enabling us to more accurately quantify diffuse fibrosis and potentially detect early fibrosisrelated changes not always detectable by LGE [13]. Indeed, increases in ECV seen on CMR are associated with an increased mortality and may be as important to prognosis as left ventricular ejection fraction $[13,14 \bullet \bullet]$. In-depth discussion of the advantages and limitations of native T1 mapping are beyond the scope of this review and have been described elsewhere [8, 11•]; instead, this review will focus on ECV imaging, which combines pre- and post-contrast images.

\section{Evolution of ECV by CMR}

Initial validation in humans utilizing $\mathrm{CMR}$ to quantify $\mathrm{ECV}$ $\left(\mathrm{ECV}_{\mathrm{CMR}}\right)$ and in turn diffuse myocardial fibrosis was performed in 2010 by Flett et al. [15]. They employed a technique they termed 'equilibrium contrast CMR', which involved an initial bolus of GBCA, followed by a continuous infusion to achieve an equilibrium of contrast between the blood pool and the myocardium [15]. They estimated the blood volume of distribution from 1-haematocrit and then used CMR to measure the pre- and post-contrast equilibrium T1 [15]. Using the formula below, they then calculated the ECV.

$\mathrm{ECV}_{\mathrm{CMR}}=(1$-haematocrit $) \times\left(\Delta\left(1 / \mathrm{T} 1_{\text {myo }}\right) / \Delta\left(1 / \mathrm{T}_{\text {blood }}\right)\right)$

They validated this technique by direct comparison with histological fibrosis quantification using picrosirius red staining on surgical biopsy samples from patients undergoing aortic valve replacement for aortic stenosis (AS, $n=18$ ) and myomectomy for hypertrophic cardiomyopathy (HCM, $n=8)$ and showed excellent correlation (combined $\left.r^{2}=0.80\right)$ [15]. Similar studies correlating ECV $_{\mathrm{CMR}}$ with histology have been reproduced in patients with aortic and mitral regurgitation [16], dilated cardiomyopathy (DCM) or ischaemic heart disease (IHD) awaiting cardiac transplantation [17], heart failure [18] and myocarditis [19]. See Table 1 for more details.

A significant barrier to the adoption of the $\mathrm{ECV}_{\mathrm{CMR}}$ technique was the use of the primed infusion protocol. This involved the patient being removed from the scanner after conventional LGE imaging and being given another bolus of GBCA, followed by a 15-min pause and then an infusion. The patient would then be returned to the scanner any time between 45 and $80 \mathrm{~min}$ after the bolus for repeat T1 measurement [15].

A bolus-only approach was proposed by Schelbert et al., who demonstrated in 10 volunteers that myocardial ECV $_{\mathrm{CMR}}$ could be reliably measured 15-20 min after a single bolus of GBCA [20]. Further work by White et al., this time in 147 subjects, demonstrated a strong correlation between 15-min bolus only and infusion $\mathrm{ECV}_{\mathrm{CMR}}$ measurement $\left(r^{2}=0.97\right)[21]$. They did note that when the ECV was $>40 \%$, the bolus only technique consistently measured a higher ECV than the infusion [21]. Finally, the validation of $\mathrm{ECV}_{\mathrm{CMR}}$ as part of a split-dose protocol (e.g. as part of stress perfusion) by McDiarmid et al. further increased the potential clinical utility of the technique [22]; however, there are suggestions that $\mathrm{ECV}_{\mathrm{CMR}}$ values may differ depending on the dose of GBCA used [23].

Most recently, a synthetic ECV can be automatically generated during scanning, in which the haematocrit of blood is inferred from the T1 of the blood pool (as the relationship between haematocrit and $\mathrm{R} 1\left[1 / \mathrm{T} 1_{\mathrm{Blood}}\right]$ is linear), removing the need for a blood test [24]. It has also been replicated at 1.5 and $3 \mathrm{~T}$ on other scanner platforms [25]. The key advantage of this technique is the simplification of the ECV workflow-by removing the need for blood tests to measure haematocrit, which is burdensome in busy departments, is a source of user error and introduces reporting delay. Implementation of inline synthetic ECV tools (with instantaneous ECV maps) would reduce the barriers to clinical use of ECV and potentially increase quality of care as review is immediately available.

\section{ECV by CMR in Clinical Practice}

Normal ECV values depend on the field strength, T1 mapping sequence and scanner manufacturer, but range between 20 and $26 \%$, and appear to be slightly higher in women compared to men [26]. With the exception of cardiac amyloidosis and oedema [27], increases in myocardial ECV are generally due to an increased collagen volume fraction (CVF) - making it a marker of fibrosis $[8,10 \bullet \bullet$. For example, acute myocardial infarction (MI) results in some of the highest ECV values $(58.5 \pm 7.6 \%)$ and chronic MI is not far behind $(51 \pm 8 \%)$ [26, 28]. Diffuse fibrosis, however, rarely increases beyond $40 \%$. Cardiac amyloidosis, which is characterized by the extracellular deposition of misfolded protein, produces large increases in ECV (greater than any other non-ischemic cardiomyopathy) in the region of $46.6 \pm 7 \%$ [26, 27, 29].

ECV is also mildly elevated in both hypertrophic cardiomyopathy $(29.1 \pm 0.5 \%)$ and dilated cardiomyopathy $(28 \pm$ $0.4 \%$ ) [26]. On the other hand, Anderson Fabry disease appears to have a similar ECV to healthy volunteers $(25.0 \pm$ $2.3 \%$ ), at least in the early stages of the disease [8, 26]. For an overview of ECV variability in health and disease, see Fig. 1 and Table 2.

\section{Evolution of ECV by CT}

ECV imaging by cardiac $\mathrm{CT}\left(\mathrm{ECV}_{\mathrm{CT}}\right)$ lags behind the CMR field, but is potentially an attractive alternative. 
Table 1 Histological validation of ECV by modality

\begin{tabular}{|c|c|c|c|c|}
\hline Reference & Year & Population & Number & Finding \\
\hline \multicolumn{5}{|l|}{ ECV by CMR } \\
\hline Flett et al. [15] & 2010 & $\mathrm{AS} / \mathrm{HCM}$ & 26 & $\begin{array}{l}\text { Strong correlation with histological fibrosis in AS } \\
\left(r^{2}=0.86\right) \text { and } \operatorname{HCM}\left(r^{2}=0.62\right) \text {. }\end{array}$ \\
\hline White et al. [21] & 2013 & AS & 18 & $\begin{array}{l}\text { Bolus only and infusion ECV measurements correlated } \\
\text { with histological CVF }\left(r^{2}=0.69 \text { and } 0.71\right) \text {. }\end{array}$ \\
\hline Miller et al. [17] & 2013 & DCM/IHD (transplant) & 6 & $\begin{array}{l}\text { Significant linear relationship with histological CVF } \\
\text { using either the } 10 \text { - or } 15 \text {-min post-contrast T1 }(p<0.001) \text {. }\end{array}$ \\
\hline De Meester et al. [16] & 2015 & $\mathrm{AS} / \mathrm{AR} / \mathrm{MR}$ & 31 & $\begin{array}{l}\text { Strong correlation with the magnitude } \\
\text { of histological fibrosis }(r=0.78) \text {. }\end{array}$ \\
\hline Kammerlander et al. [18] & 2016 & Mixed HF & 36 & Significant correlation with histological CVF $(r=0.493)$. \\
\hline Lurz et al. [19] & 2016 & Myocarditis & 129 & $\begin{array}{l}\text { ECV adequately estimated the degree of } \mathrm{LV} \text { fibrosis percentage } \\
\text { only in patients without inflammation }(\mathrm{r}=0.72) \text { and not } \\
\text { in those with inflammation }(r=0.24) \text {. }\end{array}$ \\
\hline \multicolumn{5}{|l|}{ ECV by CT } \\
\hline Bandula et al. [34] & 2013 & AS & 23 & Strong correlation with histological measures of fibrosis $(r=0.71)$. \\
\hline Yoon et al. [43] & 2015 & Hepatic fibrosis & 141 & Significant correlation with histological hepatic fibrosis staging $(r=0.493)$. \\
\hline
\end{tabular}

$A S$ aortic stenosis, $A R$ aortic regurgitation, $C V F$ collagen volume fraction, $D C M$ dilated cardiomyopathy, $H C M$ hypertrophic cardiomyopathy, $H F$ heart failure, $I H D$ ischemic heart disease, $M R$ mitral regurgitation

$\mathrm{ECV}_{\mathrm{CT}}$ relies upon the same principle as $\mathrm{ECV}_{\mathrm{CMR}}$ and is calculated using the following formula:

$\mathrm{ECV}_{\mathrm{CT}}=(1-$ haematocrit $) \times\left(\Delta \mathrm{HU}_{\text {myo }} / \Delta \mathrm{HU}_{\text {blood }}\right)$

where $\Delta H U$ is the change in Hounsfield unit attenuation pre- and post-contrast (i.e. $\mathrm{HU}_{\text {post-contrast }}-\mathrm{HU}_{\text {pre-contrast }}$ ) [30-32].

Fig. 1 Extracellular volume fraction $(\mathrm{ECV})$ variability and outcome at $1.5 \mathrm{~T}$ by myocardial pathologies. Top panel depicts ECV and associated outcome across health and disease with increasing ECV on the $y$-axis and outcome on the $x$-axis. Bottom panel shows four exemplar ECV maps of a healthy volunteer with normal ECV of $24 \%$ (a), a patient with aortic stenosis with mild ECV elevation at $30 \%$ (b), a patient with an inferior myocardial infarct (c), and a patient with AL cardiac amyloidosis with an ECV of 50\% and the poorest outcome (d). (Adapted from Ugander 2014) [86]
Early data was presented in abstract form by Ugander et al. in 2011, which showed, in dogs that underwent coronary occlusion and reperfusion $(n=10)$, that $\mathrm{ECV}_{\mathrm{CT}}$ and $\mathrm{ECV}_{\mathrm{CMR}}$ correlated well $\left(R^{2}=0.80, p<0.001\right)$, with a small mean difference between $\mathrm{ECV}_{\mathrm{CMR}}$ and $\operatorname{ECV}_{\mathrm{CT}}(3 \pm 9 \%)$ [33]. Myocardial $\mathrm{ECV}_{\mathrm{CT}}$ was first validated in humans by Nacif et al. in 2012 [30]. They compared $\mathrm{ECV}_{\mathrm{CMR}}$ and $\mathrm{ECV}_{\mathrm{CT}}$ in

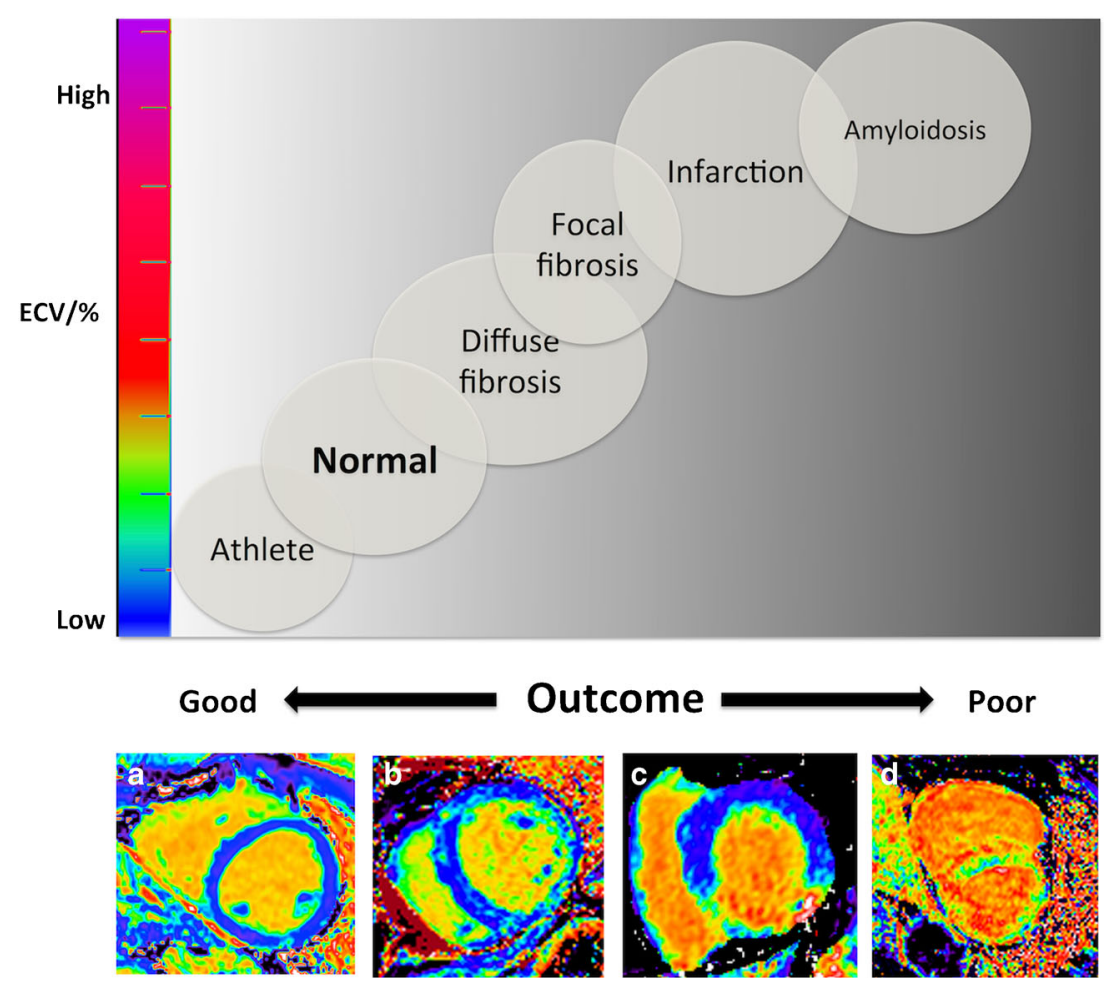


Table 2 Overview of ECV imaging in myocardial disease

\begin{tabular}{|c|c|c|c|}
\hline Process & Disease & Number of patients & $\mathrm{ECV}$ \\
\hline \multicolumn{4}{|l|}{ Athletic hypertrophy } \\
\hline & Physiological hypertrophy [12•] & 30 & $\downarrow$ \\
\hline \multicolumn{4}{|l|}{ Fibrosis } \\
\hline Focal & Myocardial infarction $[26,28]$ & 56 & $\uparrow \uparrow \uparrow$ \\
\hline \multirow[t]{10}{*}{ Diffuse } & Aortic stenosis $[26,61,62]$ & 136 & $-/ \uparrow$ \\
\hline & Systolic heart failure [63] & 40 & $\uparrow$ \\
\hline & Diastolic heart failure [63] & 62 & $\uparrow$ \\
\hline & Hypertrophic cardiomyopathy $[64,65]$ & 102 & $\uparrow$ \\
\hline & Non-ischemic dilated cardiomyopathy $[65,66]$ & 116 & $\uparrow$ \\
\hline & Mitochondrial cardiomyopathy [67] & 1 & $\uparrow$ \\
\hline & Diabetes $[14 \bullet \bullet]$ & 231 & $\uparrow$ \\
\hline & Hypertensive heart disease $[68,69]$ & 89 & - \\
\hline & Obesity [70] & 21 & $\uparrow$ \\
\hline & Congenital heart disease [71] & 14 & $\uparrow$ \\
\hline \multicolumn{4}{|l|}{ Inflammation } \\
\hline & Rheumatoid arthritis [72] & 39 & $\uparrow \uparrow$ \\
\hline & Systemic sclerosis $[73,74]$ & 49 & $\uparrow \uparrow$ \\
\hline & Systemic lupus erythematosus [75] & 33 & $\uparrow \uparrow$ \\
\hline \multicolumn{4}{|l|}{ Oedema } \\
\hline Regional & Myocarditis [76, 77] & 135 & $\uparrow$ \\
\hline \multirow[t]{3}{*}{ Global } & Anti-synthetase syndrome [78] & 1 & $\uparrow \uparrow$ \\
\hline & Chronic systemic capillary leak syndrome [79] & 6 & $\uparrow \uparrow$ \\
\hline & Acute cardiac allograft rejection $[80]$ & 22 & - \\
\hline \multicolumn{4}{|l|}{ Infiltration } \\
\hline \multirow[t]{2}{*}{ Amyloid } & AL amyloid [81] & 100 & $\uparrow \uparrow \uparrow$ \\
\hline & TTR amyloidosis [82] & 102 & $\uparrow \uparrow \uparrow$ \\
\hline Glycosphingolipid & Anderson-Fabry disease [83] & 31 & - \\
\hline \multicolumn{4}{|l|}{ Toxins } \\
\hline & Uraemia in chronic kidney disease [84] & 43 & $\uparrow$ \\
\hline & Anthracycline-toxicity $[85]$ & 30 & $-1 \uparrow$ \\
\hline
\end{tabular}

Reference list is non-exhaustive - several other references may exist that are not listed here

— No significant change; $\uparrow$ Significant increase; $\downarrow$ Significant decrease.

(Adapted from Captur et al. Heart 2016, Sep 15;102 (18):1429-35, with permission from BMJ Publishing Group Ltd.) [87].

24 subjects (both healthy volunteers and those with heart failure) and found good correlation between the two $(r=0.82$, $p<0.001$ ) [30]. Post-contrast images were taken after a 10 min delay, copying the exact parameters of the initial precontrast calcium score scan. Overall radiation dose was low $(<2 \mathrm{mSv})$ [30]. The average duration of $\mathrm{ECV}_{\mathrm{CT}}$ in this study was $13 \pm 1.5 \mathrm{~min}$, compared to $47 \pm 5 \mathrm{~min}$ for $\mathrm{ECV}_{\mathrm{CMR}}$ [30]. $\mathrm{ECV}_{\mathrm{CMR}}$ results were slightly lower $(28.6 \pm 4.4 \%)$ compared to $\mathrm{ECV}_{\mathrm{CT}}(31.6 \pm 5.1 \%)$ [30]. The same group went on to compare $\mathrm{ECV}_{\mathrm{CT}}$ in healthy volunteers and those with either systolic or diastolic heart failure [31]. They used a similar protocol, only this time, taking the post-contrast images after a shorter 7-min delay [31]. They found that the ECV was significantly higher in participants with systolic heart failure
(41 $\pm 6 \%)$ compared to healthy subjects $(33 \pm 2 \%)$ and those with diastolic heart failure $(35 \pm 5 \%)$ [31].

Bandula et al. in the same year validated $\mathrm{ECV}_{\mathrm{CT}}$ against the gold standard - invasive endomyocardial biopsy, as well as $\mathrm{ECV}_{\mathrm{CMR}}$ in 23 patients with severe aortic stenosis [34]. This time, they used an initial bolus of contrast agent, followed by a slow infusion to achieve equilibrium. They found that $\mathrm{ECV}_{\mathrm{CT}}$ showed significant correlation with both histological measures of fibrosis $(r=0.71, p<0.001)$ and $\mathrm{ECV}_{\mathrm{CMR}}(r=0.73)$ [34]. We subsequently compared 5-and 15-minute time points post-contrast bolus for equilibrium cardiac CT in 53 patients (26 with systemic amyloidosis and 27 with aortic stenosis) [32]. We demonstrated that $\mathrm{ECV}_{\mathrm{CT}}$ at 5-minute post-contrast showed a stronger correlation with $\mathrm{ECV}_{\mathrm{CMR}}$ than at 15-minute 
post-contrast $\left(r^{2}=0.85\right.$ compared to 0.74$)$ [32]. We think this is because, although earlier imaging risks non-equilibration, iodine is a weaker contrast agent than GBCAs, so the higher signal-to-noise ratio of earlier imaging outweighs this. $\mathrm{ECV}_{\mathrm{CT}}$ was consistently higher in those patients with confirmed cardiac amyloid compared to those with aortic stenosis $(54 \pm 11 \%$ compared to $28 \pm 4 \%, p<0.001)$ and was able to discriminate between patients with definite cardiac amyloid and those with aortic stenosis in all cases [32]. $\mathrm{ECV}_{\mathrm{CT}}$ also tracked various important clinical parameters including reduced 6-min walk test distance and increasing NT-proBNP, as well as amyloid burden in transthyretin-related amyloid - when measured semi-quantitatively by $99 \mathrm{mTc}-3,3$-diphsphono-1,2propanodicarboxylic acid (DPD) scintigraphy [32].

Work is also being done using dual-energy CT to quantify myocardial ECV, which is an attractive concept, as it would potentially avoid mis-registration errors associated with the separate pre- and post-contrast scans, by obviating the need for the pre-contrast scan $[35,36]$. Hong et al. used dual-energy $\mathrm{CT}$ to estimate myocardial ECV in doxorubicin-induced dilated cardiomyopathy in rabbits [36]. They showed equivalent ECV results by dual-energy CT from 3 up to 20 minute postcontrast administration [36]. ECV values were significantly higher at 6,12 and 16 weeks after starting twice weekly doxorubicin injections than at baseline $(35.3,41.9,42.1 \%$ vs. $28.5 \%$ ) [36]. ECV measured by dual-energy CT showed excellent correlation with $\mathrm{ECV}_{\mathrm{CMR}}(r=0.888, p<0.001)$ and with collagen volume fraction on histology $(r=0.925$, $p<0.001$ ) [36]. Work has also been done in humans using dual energy CT-involving 30 subjects ( 7 healthy, 23 with hypertrophic or dilated cardiomyopathy, amyloidosis or sarcoidosis) [37]. The post-contrast dual-energy CT scan was performed at 12 minute and results for ECV were compared with $\mathrm{CMR}_{\mathrm{ECV}}$ and showed good agreement. Those participants with disease had significantly higher myocardial ECV by dual-energy CT compared to healthy subjects $(p<0.01)$ [37].

More recently, synthetic ECV has also been successfully implemented in CT, where the haematocrit of blood is inferred from the attenuation of the blood pool (as the relationship between haematocrit and $\mathrm{HU}$ is also linear), simplifying the ECV workflow and allowing instantaneous display of ECV maps [38].

\section{CT versus CMR for Myocardial ECV Quantification}

While the evidence base for $\mathrm{ECV}_{\mathrm{CMR}}$ may be larger and experience greater, the use of $\mathrm{CT}$ in this regard does have some distinct advantages. Likely to prove the biggest advantage is that $\mathrm{ECV}_{\mathrm{CT}}$ measures the direct effect of iodine-based contrast agents on the measured signal (through the effect of iodine on x-ray absorption), whereas $\mathrm{ECV}_{\mathrm{CMR}}$ relies on measuring the effect of GBCAs on protons (therefore making two assumptions - the first is that the relaxivity of tissues compared to blood is the same and the second is that water is rapidly exchanged between intra- and extracellular compartments). Also, common contraindications to CMR such as claustrophobia and pacemaker implantation (the latter being not uncommon in patients with for example cardiac amyloid - where ECV quantification could prove helpful) do not apply for CT.

$\mathrm{ECV}_{\mathrm{CMR}}$ is likely to be costly, both financially and in terms of patient throughput - with scans taking up to $60 \mathrm{~min}$, whereas CT scans are significantly faster and more widely available. Indeed, CT availability is only likely to increase, particularly in the UK, given the expanded role for CT coronary angiography in the 2016 update of the National Institute for Health and Care Excllence clinical guideline (CG95) on the assessment of chest pain of recent onset [39]. CT also offers higher spatial resolution particularly inplane and allows isotropic reconstruction. Of course, these potential advantages should be weighed up against the risks of ionizing radiation from $\mathrm{CT}$, especially in younger patients. Furthermore, $\mathrm{CT}$ is also prone to artefacts, e.g. beam hardening and streak artefacts that may hamper the evaluation of myocardial ECV. Finally, in delayed acquisitions, iodine contrast media provide less signal compared to GBCAs and differentiation between myocardium and left ventricular cavity is hampered, particularly when the myocardium is thinned (for example in dilated cardiomyopathy).

GBCAs have been associated with the development of nephrogenic systemic fibrosis, seen with linear chelates rather than macrocyclic and in patients with significantly impaired renal function $\left(\mathrm{eGFR}<30 \mathrm{~mL} / \mathrm{min} / 1.73 \mathrm{~m}^{2}\right.$ ) [40]. These linear agents have also been associated with brain deposition, a currently evolving story (but apparently not seen with macrocyclic chelates [41]. Iodinated contrast agents have in turn been associated with contrast-induced nephropathy and preexisting chronic kidney disease (eGFR $<60 \mathrm{~mL} / \mathrm{min} / 1.73 \mathrm{~m}^{2}$ ) is the most important risk factor for this [42].

It is important to bear in mind while considering the pros and cons of both of these modalities that relative to the current gold standard for diagnosing diffuse fibrosis of invasive endomyocardial biopsy, both offer very attractive alternatives.

\section{$\mathrm{ECV}_{\mathrm{CT}}$ in Clinical Practice-from Research Tool to Clinical Application}

For clinical utilization, there needs to be standardized protocols in place for performing $\mathrm{ECV}_{\mathrm{CT}}$. Furthermore, we need to employ this technique to better diagnose and understand disease processes and the effect of treatment on ECV (for example as a surrogate end point in drug trials). This has been implemented in the T1 mapping consensus statement, with a second version to be published in mid- 
2017 [10••]. For $\mathrm{ECV}_{\mathrm{CT}}$ to become a technique used in clinical practice, key steps need to be implemented-similar to developments in the CMR community, in particular standardization with phantom work, multicentre clinical data in health and disease, a consensus statement by national/international organizations (e.g. EACVI/SCCT) and adoption by all major manufacturers.

\section{ECV Quantification beyond the Myocardium}

The potential for $\mathrm{ECV}_{\mathrm{CT}}$ and $\mathrm{ECV}_{\mathrm{CMR}}$ extends beyond the myocardium. Yoon et al. used CT to estimate liver ECV in order to measure hepatic fibrosis and validated this against histological hepatic fibrosis staging in 141 participants $(r=$ $0.493, p<0.001$ ) [43]. Bandula et al. also demonstrated elevated $\mathrm{ECV}_{\mathrm{CMR}}$ in the liver, spleen and skeletal muscle in patients with systemic amyloidosis, which tracked semiquantitative amyloid burden in the liver and spleen by serum amyloid P component (SAP) scintigraphy [44]. Similar work has been performed by Yeung et al. using ECV $_{\mathrm{CT}}$ [45]. They showed that in patients with hepatic and splenic amyloid, there was a significantly higher ECV compared to patients without liver and spleen involvement $(p<0.0005)$ [45]. They were also able to show that increases in $\mathrm{ECV}_{\mathrm{CT}}$ positively correlated with the grade of hepatic and splenic uptake on SAP scintigraphy $(r=0.758$ for liver, $r=0.867$ for spleen) [45].

\section{Future Outlook for CT}

Currently, a poorer signal-to-noise ratio than CMR and the use of ionizing radiation have impeded wider application of myocardial tissue characterization by CT. Nevertheless, the possibility of providing an assessment of coronary anatomy, coronary flow and myocardial tissue characterization in a single modality is an attractive concept, with huge implications for imaging workflow.

Beyond the optimization of dual-energy CT with minimization of image artefacts, radiation dose and iodinated contrast dose (e.g. using low-energy monochromatic imaging [46]), more advanced technologies are on the horizon. Spectral CT imaging exploits the different K-edge behaviour of different tissues (calcium, blood, fat and myocardium) [47]. This technology goes beyond the two-photon energy levels used in dual-energy CT, and utilizes energy-sensitive photoncounting detectors to obtain greater tissue information by differentiating photons at different energy levels. Early preclinical data suggests that spectral CT may improve image quality over conventional CT by eliminating beam hardening [48].

\section{Future Outlook for CMR}

The T1 mapping field has been rapidly advancing to the point of widespread clinical utility. Since the first T1 quantification with the original modified look-locker imaging (MOLLI) in 2004 [49], new MOLLI variants, ShMOLLI (a shortened variation with long T1 advantages) [50], saturation recovery variants such as SASHA (offering complete heart rate insensitivity) [51] or hybrid approaches [52-54] have been developed, and incremental developments such as respiratory motion correction [55] have gradually increased accuracy and precision $[52,56 \bullet$. ECV maps are now routine in some centres [57], but ECV development and standardization are still on-going and will require global approaches. Quality control systems, commercial sequences, mega-registries (e.g. the Global CMR Registry, HCM Registry and UK Biobank) are in progress, and will provide high volumes and new insights into the currently most active CMR research area [58, 59]. On the horizon, MR fingerprinting may offer more rapid multi-parametric tissue characterization in the future by providing myocardial T1, T2, and Proton Spin Density in a single breath-hold [60].

\section{Conclusion}

Myocardial ECV is important, with increases related to myocardial fibrosis, cardiac amyloid or oedema, which in turn are associated with an increased mortality. Quantification of ECV enables the detection of diffuse myocardial fibrosis, which would otherwise potentially be missed using conventional LGE imaging, making it a useful addition to the armamentarium of myocardial characterization techniques.

CT and CMR can be used to estimate myocardial ECV and in turn diffuse myocardial fibrosis, without the need for invasive endomyocardial biopsy. Each modality has strengths and weaknesses, with CT an attractive alternative to CMR particularly in those with contraindications to the latter. Further studies are needed in this field, especially $\mathrm{ECV}_{\mathrm{CT}}$, where the evidence base is less robust.

Funding Paul R. Scully is supported by a British Heart Foundation Clinical Research Training Fellowship (FS/16/31/32185). James C. Moon is directly and indirectly supported by the University College London Hospitals NIHR Biomedical Research Centre and Biomedical Research Unit at Barts Hospital, respectively. Thomas Treibel was supported by doctoral research fellowship from the National Institute of Health Research (NIHR; DRF-2013-06-102).

\section{Compliance with Ethical Standards}

Conflict of Interest Paul R. Scully, James C. Moon, and Thomas A. Treibel declare that they have no conflict of interest.

Gorka Bastarrika reports other from Siemens Healthcare, General Electric, and Bayer. 
Human and Animal Rights and Informed Consent This article does not contain any studies with human or animal subjects performed by any of the authors.

Open Access This article is distributed under the terms of the Creative Commons Attribution 4.0 International License (http:// creativecommons.org/licenses/by/4.0/), which permits unrestricted use, distribution, and reproduction in any medium, provided you give appropriate credit to the original author(s) and the source, provide a link to the Creative Commons license, and indicate if changes were made.

\section{References}

Papers of particular interest, published recently, have been highlighted as:

- Of importance

•- Of major importance

1. Mewton N, Liu CY, Croisille P, Bluemke D, Lima JAC. Assessment of myocardial fibrosis with cardiovascular magnetic resonance. J Am Coll Cardiol. 2011;57:891-903. https://doi.org/ 10.1016/j.jacc.2010.11.013.

2. Anderson KR, Sutton MGSJ, Lie JT. Histopathological types of cardiac fibrosis in myocardial disease. J Pathol. 1979;128:79-85. https://doi.org/10.1002/path.1711280205.

3. Kim RJ, Albert TSE, Wible JH, Elliott MD, Allen JC, Lee JC, et al. Performance of delayed-enhancement magnetic resonance imaging with gadoversetamide contrast for the detection and assessment of myocardial infarction: an international, multicenter, doubleblinded, randomized trial. Circulation. 2008;117:629-37. https:// doi.org/10.1161/CIRCULATIONAHA.107.723262.

4. Lusic H, Grinstaff MW. X-ray-computed tomography contrast agents. Chem Rev. 2013;113:1641-66. https://doi.org/10.1021/ cr200358s.

5. Oliva MR, Mortele KJ. Iodinated contrast agents for cardiac CT. In: Di Carli MF, Lipton MJ, editors Card PET PETCT Imaging, New York, NY: Springer New York; 2007, p. 83-93. doi:https://doi.org/ 10.1007/978-0-387-38295-1_6.

6. Nicol E, Stirrup J, Kelion AD, Padley SPG. Cardiovascular computed tomography. Oxford: OUP Oxford; 2011.

7. Deray G. Dialysis and iodinated contrast media. Kidney Int. 2006;69:S25-9. https://doi.org/10.1038/sj.ki.5000371.

8. Haaf P, Garg P, Messroghli DR, Broadbent DA, Greenwood JP, Plein S. Cardiac T1 mapping and extracellular volume (ECV) in clinical practice: a comprehensive review. J Cardiovasc Magn Reson. 2017;18:89. https://doi.org/10.1186/s12968-016-0308-4.

9. Parsai C, O'Hanlon R, Prasad SK, Mohiaddin RH. Diagnostic and prognostic value of cardiovascular magnetic resonance in nonischaemic cardiomyopathies. J Cardiovasc Magn Reson. 2012;14: 54. https://doi.org/10.1186/1532-429X-14-54.

10.• Moon JC, Messroghli DR, Kellman P, Piechnik SK, Robson MD, Ugander M, et al. Myocardial T1 mapping and extracellular volume quantification: a Society for Cardiovascular Magnetic Resonance (SCMR) and CMR Working Group of the European Society of Cardiology consensus statement. J Cardiovasc Magn Reson. 2013;15:92. https://doi.org/10.1186/1532-429X-15-92. The SCMR consensus statement on T1 mapping and ECV is an essential read for anybody interested in this field; an updated consensus statement is due to be published in the second half of 2017.
11. Puntmann VO, Peker E, Chandrashekhar Y, Nagel E. T1 mapping in characterizing myocardial disease: a comprehensive review. Circ Res. 2016;119:277-99. https://doi.org/10.1161/CIRCRESAHA. 116.307974. Very good recent review of T1 mapping and ECV by CMR.

12. McDiarmid AK, Swoboda PP, Erhayiem B, Lancaster RE, Lyall GK, Broadbent DA, et al. Athletic cardiac adaptation in males is a consequence of elevated myocyte mass. Circ Cardiovasc Imaging. 2016;9: e003579. https://doi.org/10.1161/CIRCIMAGING.115.003579. This paper elegantly shows that ECV actually falls in physiological hypertrophy due to isolated cell hypertrophy.

13. Wong TC, Piehler K, Meier CG, Testa SM, Klock AM, Aneizi AA, et al. Association between extracellular matrix expansion quantified by cardiovascular magnetic resonance and short-term mortality. Circulation. 2012;126:1206-16. https://doi.org/10.1161/ CIRCULATIONAHA.111.089409.

14.• Wong TC, Piehler KM, Kang IA, Kadakkal A, Kellman P, Schwartzman DS, et al. Myocardial extracellular volume fraction quantified by cardiovascular magnetic resonance is increased in diabetes and associated with mortality and incident heart failure admission. Eur Heart J. 2014;35:657-64. https://doi.org/10.1093/ eurheartj/eht193. This paper identifies ECV as an independent marker of death and heart failure in one of the largest ECV outcome cohorts.

15. Flett AS, Hayward MP, Ashworth MT, Hansen MS, Taylor AM, Elliott PM, et al. Equilibrium contrast cardiovascular magnetic resonance for the measurement of diffuse myocardial fibrosis: preliminary validation in humans. Circulation. 2010;122:138-44. https:// doi.org/10.1161/CIRCULATIONAHA.109.930636.

16. de Meester Ravenstein C, Bouzin C, Lazam S, Boulif J, Amzulescu $\mathrm{M}$, Melchior J, et al. Histological validation of measurement of diffuse interstitial myocardial fibrosis by myocardial extravascular volume fraction from modified look-locker imaging (MOLLI) T1 mapping at 3 T. J Cardiovasc Magn Reson. 2015;17:48. https://doi. org/10.1186/s12968-015-0150-0.

17. Miller CA, Naish JH, Bishop P, Coutts G, Clark D, Zhao S, et al. Comprehensive validation of cardiovascular magnetic resonance techniques for the assessment of myocardial extracellular volume. Circ Cardiovasc Imaging. 2013;6:373-83. https://doi.org/10.1161/ CIRCIMAGING.112.000192.

18. Kammerlander AA, Marzluf BA, Zotter-Tufaro C, Aschauer S, Duca F, Bachmann A, et al. T1 Mapping by CMR Imaging. JACC Cardiovasc Imaging. 2016;9:14-23. https://doi.org/10. 1016/j.jcmg.2015.11.002

19. Lurz P, Luecke C, Eitel I, Fohrenbach F, Frank C, Grothoff M, et al. Comprehensive cardiac magnetic resonance imaging in patients with suspected myocarditis. J Am Coll Cardiol. 2016;67:1800-11. https://doi.org/10.1016/j.jacc.2016.02.013.

20. Schelbert EB, Testa SM, Meier CG, Ceyrolles WJ, Levenson JE, Blair AJ, et al. Myocardial extravascular extracellular volume fraction measurement by gadolinium cardiovascular magnetic resonance in humans: slow infusion versus bolus. J Cardiovasc Magn Reson. 2011;13:16. https://doi.org/10.1186/1532-429X-13-16.

21. White SK, Sado DM, Fontana M, Banypersad SM, Maestrini V, Flett AS, et al. T1 mapping for myocardial extracellular volume measurement by CMR. JACC Cardiovasc Imaging. 2013;6:95562. https://doi.org/10.1016/j.jcmg.2013.01.011.

22. McDiarmid AK, Swoboda PP, Erhayiem B, Ripley DP, Kidambi A, Broadbent DA, et al. Single bolus versus split dose gadolinium administration in extra-cellular volume calculation at 3 Tesla. $\mathbf{J}$ Cardiovasc Magn Reson. 2015;17:6. https://doi.org/10.1186/ s12968-015-0112-6.

23. Caballeros M, Bartolomé P, Fernández González Ó, Greiser A, García del Barrio L, Pueyo J, et al. Effect of contrast dose in the quantification of myocardial extra-cellular volume in adenosine stress/rest perfusion cardiac magnetic resonance examinations. 
Acta Radiol. 2017;58:809-15. https://doi.org/10.1177/ 0284185116674501.

24. Treibel TA, Fontana M, Maestrini V, Castelletti S, Rosmini S, Simpson J, et al. Automatic measurement of the myocardial Interstitium. JACC Cardiovasc Imaging. 2016;9:54-63. https:// doi.org/10.1016/j.jcmg.2015.11.008.

25. Fent GJ, Garg P, Foley JRJ, Swoboda PP, Dobson LE, Erhayiem B, et al. Synthetic myocardial extracellular volume fraction. JACC Cardiovasc Imaging. 2017;10:1402-4. https://doi.org/10.1016/j. jemg.2016.12.007.

26. Sado DM, Flett AS, Banypersad SM, White SK, Maestrini V, Quarta G, et al. Cardiovascular magnetic resonance measurement of myocardial extracellular volume in health and disease. Heart. 2012;98:1436-41. https://doi.org/10.1136/heartjnl-2012-302346.

27. Banypersad SM, Sado DM, Flett AS, Gibbs SDJ, Pinney JH, Maestrini V, et al. Quantification of myocardial extracellular volume fraction in systemic $\mathrm{AL}$ amyloidosis: an equilibrium contrast cardiovascular magnetic resonance study. Circ Cardiovasc Imaging. 2013;6:34-9. https://doi.org/10.1161/CIRCIMAGING. 112.978627 .

28. Ugander M, Oki AJ, Hsu L-Y, Kellman P, Greiser A, Aletras AH, et al. Extracellular volume imaging by magnetic resonance imaging provides insights into overt and sub-clinical myocardial pathology. Eur Heart J. 2012;33:1268-78. https://doi.org/10.1093/eurheartj/ ehr481.

29. Banypersad SM, Moon JC, Whelan C, Hawkins PN, Wechalekar AD. Updates in cardiac amyloidosis: a review. J Am Heart Assoc. 2012;1:e00364. https://doi.org/10.1161/JAHA.111.000364.

30. Nacif MS, Kawel N, Lee JJ, Chen X, Yao J, Zavodni A, et al. Interstitial myocardial fibrosis assessed as extracellular volume fraction with low-radiation-dose cardiac CT. Radiology. 2012;264:876-83. https://doi.org/10.1148/radiol.12112458.

31. Nacif MS, Liu Y, Yao J, Liu S, Sibley CT, Summers RM, et al. 3D left ventricular extracellular volume fraction by low-radiation dose cardiac CT: assessment of interstitial myocardial fibrosis. J Cardiovasc Comput Tomogr. 2013;7:51-7. https://doi.org/10. 1016/j.jcct.2012.10.010

32. Treibel TA, Bandula S, Fontana M, White SK, Gilbertson JA, Herrey AS, et al. Extracellular volume quantification by dynamic equilibrium cardiac computed tomography in cardiac amyloidosis. J Cardiovasc Comput Tomogr. 2015;9:585-92. https://doi.org/10. 1016/j.jcct.2015.07.001.

33. Ugander M, Chen MY, Chen B, Bagi PS, Hsu L-Y, Kellman P, et al. Abstract 16534: contrast enhanced CT and MRI measures of extracellular volume fraction confirm presence of peri-infarct edema in acute myocardial infarction. Circulation. 2011;124:A16534

34. Bandula S, White SK, Flett AS, Lawrence D, Pugliese F, Ashworth MT, et al. Measurement of myocardial extracellular volume fraction by using equilibrium contrast-enhanced CT: validation against histologic findings. Radiology. 2013;269:396-403. https://doi.org/10. 1148/radiol.13130130.

35. Graser A, Johnson TRC, Chandarana H, Macari M. Dual energy CT: preliminary observations and potential clinical applications in the abdomen. Eur Radiol. 2009;19:13-23. https://doi.org/10.1007/ s00330-008-1122-7.

36. Hong YJ, Kim TK, Hong D, Park CH, Yoo SJ, Wickum ME, et al. Myocardial characterization using dual-energy CT in doxorubicininduced DCM. JACC Cardiovasc Imaging. 2016;9:836-45. https:// doi.org/10.1016/j.jcmg.2015.12.018.

37. Lee H-J, Im DJ, Youn J-C, Chang S, Suh YJ, Hong YJ, et al. Myocardial extracellular volume fraction with dual-energy equilibrium contrast-enhanced cardiac $\mathrm{CT}$ in nonischemic cardiomyopathy: a prospective comparison with cardiac MR imaging. Radiology. 2016;280:49-57. https://doi.org/10.1148/radiol. 2016151289
38. Treibel TA, Fontana M, Steeden JA, Nasis A, Yeung J, White SK, et al. Automatic quantification of the myocardial extracellular volume by cardiac computed tomography: synthetic ECV by CCT. J Cardiovasc Comput Tomogr. 2017;11:221-6. https://doi.org/10. 1016/j.jcct.2017.02.006.

39. National Institute for Health and Care Excellence (NICE). Chest pain of recent onset: assessment and diagnosis: clinical guideline [CG95] 2016.

40. Perez-Rodriguez J, Lai S, Ehst BD, Fine DM, Bluemke DA. Nephrogenic systemic fibrosis: incidence, associations, and effect of risk factor assessment — report of 33 cases. Radiology. 2009;250: 371-7. https://doi.org/10.1148/radiol.2502080498.

41. Kanda T, Osawa M, Oba H, Toyoda K, Kotoku J, Haruyama T, et al. High signal intensity in dentate nucleus on unenhanced T1weighted MR images: association with linear versus macrocyclic gadolinium chelate administration. Radiology. 2015;275:803-9. https://doi.org/10.1148/radiol.14140364.

42. Lameire N, Adam A, Becker CR, Davidson C, McCullough PA, Stacul F, et al. Baseline renal function screening. Am J Cardiol. 2006;98(6):21-6. https://doi.org/10.1016/j.amjcard.2006.01.021.

43. Yoon JH, Lee JM, Klotz E, Jeon JH, Lee K-B, Han JK, et al. Estimation of hepatic extracellular volume fraction using multiphasic liver computed tomography for hepatic fibrosis grading. Investig Radiol. 2015;50:290-6. https://doi.org/10.1097/RLI. 0000000000000123 .

44. Bandula S, Banypersad SM, Sado D, Flett AS, Punwani S, Taylor SA, et al. Measurement of tissue interstitial volume in healthy patients and those with amyloidosis with equilibrium contrastenhanced MR imaging. Radiology. 2013;268:858-64. https://doi. org/10.1148/radiol.13121889.

45. Yeung J, Sivarajan S, Treibel TA, Rosmini S, Fontana M, Gillmore $\mathrm{JD}$, et al. Measurement of liver and spleen interstitial volume in patients with systemic amyloid light-chain amyloidosis using equilibrium contrast CT. Abdom Radiol. 2017;42:2646-51. https://doi. org/10.1007/s00261-017-1194-4.

46. Scheske JA, O'Brien JM, Earls JP, Min JK, LaBounty TM, Cury $\mathrm{RC}$, et al. Coronary artery imaging with single-source rapid kilovolt peak-switching dual-energy CT. Radiology. 2013;268:702-9. https://doi.org/10.1148/radiol.13121901.

47. Boussel L, Coulon P, Thran A, Roessl E, Martens G, Sigovan M, et al. Photon counting spectral CT component analysis of coronary artery atherosclerotic plaque samples. Br J Radiol. 2014;87: 20130798. https://doi.org/10.1259/bjr.20130798.

48. Fahmi R, Eck BL, Levi J, Fares A, Dhanantwari A, Vembar M, et al. Quantitative myocardial perfusion imaging in a porcine ischemia model using a prototype spectral detector CT system. Phys Med Biol. 2016;61:2407-31. https://doi.org/10.1088/0031-9155/61/6/ 2407.

49. Messroghli DR, Radjenovic A, Kozerke S, Higgins DM, Sivananthan MU, Ridgway JP. Modified look-locker inversion recovery (MOLLI) for high-resolution T1 mapping of the heart. Magn Reson Med. 2004;52:141-6. https://doi.org/10.1002/mrm. 20110.

50. Piechnik SK, Ferreira VM, Dall'Armellina E, Cochlin LE, Greiser A, Neubauer S, et al. Shortened modified look-locker inversion recovery (ShMOLLI) for clinical myocardial T1-mapping at 1.5 and $3 \mathrm{~T}$ within a 9 heartbeat breathhold. J Cardiovasc Magn Reson. 2010;12:69. https://doi.org/10.1186/1532-429X-12-69.

51. Chow K, Flewitt JA, Green JD, Pagano JJ, Friedrich MG, Saturation TRB. Recovery single-shot acquisition (SASHA) for myocardial $T_{1}$ mapping: SASHA for $\mathrm{T}_{1}$ mapping. Magn Reson Med. 2014;71:2082-95. https://doi.org/10.1002/mrm.24878.

52. Roujol S, Weingärtner S, Foppa M, Chow K, Kawaji K, Ngo LH, et al. Accuracy, precision, and reproducibility of four T1 mapping sequences: a head-to-head comparison of MOLLI, ShMOLLI, 
SASHA, and SAPPHIRE. Radiology. 2014;272:683-9. https://doi. org/10.1148/radiol.14140296.

53. Mehta BB, Chen X, Bilchick KC, Salerno M, Epstein FH. Accelerated and navigator-gated look-locker imaging for cardiac t1 estimation (ANGIE): development and application to T1 mapping of the right ventricle: ANGIE: accelerated and navigator-gated look-locker imaging for cardiac T1 estimation. Magn Reson Med. 2015;73:150-60. https://doi.org/10.1002/mrm.25100.

54. Kvernby S, Warntjes MJB, Haraldsson H, Carlhäll C-J, Engvall J, Ebbers T. Simultaneous three-dimensional myocardial T1 and T2 mapping in one breath hold with 3D-QALAS. J Cardiovasc Magn Reson. 2014;16:102. https://doi.org/10.1186/s12968-014-0102-0.

55. Xue H, Greiser A, Zuehlsdorff S, Jolly M-P, Guehring J, Arai AE, et al. Phase-sensitive inversion recovery for myocardial $T_{1}$ mapping with motion correction and parametric fitting. Magn Reson Med. 2013;69:1408-20. https://doi.org/10.1002/mrm.24385.

56. Kellman P, Hansen MS. T1-mapping in the heart: accuracy and precision. J Cardiovasc Magn Reson. 2014;16:2. https://doi.org/ $10.1186 / 1532-429 X-16-2$. Key paper on the technical intricacies of T1 mapping and ECV.

57. Kellman P, Wilson JR, Xue H, Ugander M, Arai AE. Extracellular volume fraction mapping in the myocardium, part 1: evaluation of an automated method. J Cardiovasc Magn Reson. 2012;14:63. https://doi.org/10.1186/1532-429X-14-63.

58. Kramer CM, Appelbaum E, Desai MY, Desvigne-Nickens P, DiMarco JP, Friedrich MG, et al. Hypertrophic cardiomyopathy registry: the rationale and design of an international, observational study of hypertrophic cardiomyopathy. Am Heart J. 2015;170:22330. https://doi.org/10.1016/j.ahj.2015.05.013.

59. Petersen SE, Matthews PM, Bamberg F, Bluemke DA, Francis JM, Friedrich MG, et al. Imaging in population science: cardiovascular magnetic resonance in 100,000 participants of UK biobank - rationale, challenges and approaches. J Cardiovasc Magn Reson. 2013;15:46. https://doi.org/10.1186/1532-429X-15-46.

60. Hamilton JI, Jiang Y, Chen Y, Ma D, Lo W-C, Griswold M, et al. MR fingerprinting for rapid quantification of myocardial $T_{1}, T_{2}$, and proton spin density: cardiac MR fingerprinting for $\mathrm{T}_{1}, \mathrm{~T}_{2}$, and $\mathrm{M}_{0}$ mapping. Magn Reson Med. 2017;77:1446-58. https://doi.org/ $10.1002 / \mathrm{mrm} .26216$.

61. Chin CWL, Semple S, Malley T, White AC, Mirsadraee S, Weale PJ, et al. Optimization and comparison of myocardial T1 techniques at $3 \mathrm{~T}$ in patients with aortic stenosis. Eur Heart J-Cardiovasc Imaging. 2014;15:556-65. https://doi.org/10.1093/ehjci/jet245.

62. Singh A, Horsfield MA, Bekele S, Khan JN, Greiser A, McCann GP. Myocardial T1 and extracellular volume fraction measurement in asymptomatic patients with aortic stenosis: reproducibility and comparison with age-matched controls. Eur Heart J-Cardiovasc Imaging. 2015;16:763-70. https://doi.org/10.1093/ehjci/jev007.

63. Su M-YM, Lin L-Y, Tseng Y-HE, Chang C-C, Wu C-K, Lin J-L, et al. CMR-verified diffuse myocardial fibrosis is associated with diastolic dysfunction in HFpEF. JACC Cardiovasc Imaging. 2014;7:991-7. https://doi.org/10.1016/j.jcmg.2014.04.022.

64. Ho CY, Abbasi SA, Neilan TG, Shah RV, Chen Y, Heydari B, et al. T1 measurements identify extracellular volume expansion in hypertrophic cardiomyopathy sarcomere mutation carriers with and without left ventricular hypertrophy. Circ Cardiovasc Imaging. 2013;6: 415-22. https://doi.org/10.1161/CIRCIMAGING.112.000333.

65. Puntmann VO, Voigt T, Chen Z, Mayr M, Karim R, Rhode K, et al. Native T1 mapping in differentiation of normal myocardium from diffuse disease in hypertrophic and dilated cardiomyopathy. JACC Cardiovasc Imaging. 2013;6:475-84. https://doi.org/10.1016/j. jcmg.2012.08.019.

66. Barison A, Del Torto A, Chiappino S, Aquaro GD, Todiere G, Vergaro G, et al. Prognostic significance of myocardial extracellular volume fraction in nonischaemic dilated cardiomyopathy. J
Cardiovasc Med. 2015;16:681-7. https://doi.org/10.2459/JCM. 0000000000000275.

67. Lee KH, Park HS, Park CH, Kim K-H, Chung H, Kim TH, et al. Extracellular volume imaging and quantitative T2 mapping for the diagnosis of mitochondrial cardiomyopathy. Circulation. 2014;130: 1832-4. https://doi.org/10.1161/CIRCULATIONAHA.114. 010779 .

68. Kuruvilla S, Janardhanan R, Antkowiak P, Keeley EC, Adenaw N, Brooks J, et al. Increased extracellular volume and altered mechanics are associated with LVH in hypertensive heart disease, not hypertension alone. JACC Cardiovasc Imaging. 2015;8:172-80. https://doi.org/10.1016/j.jcmg.2014.09.020.

69. Treibel TA, Zemrak F, Sado DM, Banypersad SM, White SK, Maestrini V, et al. Extracellular volume quantification in isolated hypertension - changes at the detectable limits? J Cardiovasc Magn Reson. 2015;17:74. https://doi.org/10.1186/s12968-015-0176-3.

70. Shah RV, Abbasi SA, Neilan TG, Hulten E, Coelho-Filho O, Hoppin A, et al. Myocardial tissue remodeling in adolescent obesity. J Am Heart Assoc. 2013;2:e000279. https://doi.org/10.1161/ JAHA.113.000279.

71. Plymen CM, Sado DM, Taylor AM, Bolger AP, Lambiase PD, Hughes M, et al. Diffuse myocardial fibrosis in the systemic right ventricle of patients late after mustard or Senning surgery: an equilibrium contrast cardiovascular magnetic resonance study. Eur Heart J-Cardiovasc Imaging. 2013;14:963-8. https://doi.org/10. 1093/ehjci/jet014.

72. Ntusi NAB, Piechnik SK, Francis JM, Ferreira VM, Matthews PM, Robson MD, et al. Diffuse myocardial fibrosis and inflammation in rheumatoid arthritis. JACC Cardiovasc Imaging. 2015;8:526-36. https://doi.org/10.1016/j.jcmg.2014.12.025.

73. Ntusi NA, Piechnik SK, Francis JM, Ferreira VM, Rai AB, Matthews PM, et al. Subclinical myocardial inflammation and diffuse fibrosis are common in systemic sclerosis - a clinical study using myocardial T1-mapping and extracellular volume quantification. J Cardiovasc Magn Reson. 2014;16:21. https://doi.org/10. 1186/1532-429X-16-21.

74. Barison A, Gargani L, De Marchi D, Aquaro GD, Guiducci S, Picano E, et al. Early myocardial and skeletal muscle interstitial remodelling in systemic sclerosis: insights from extracellular volume quantification using cardiovascular magnetic resonance. Eur Heart J-Cardiovasc Imaging. 2015;16:74-80. https://doi.org/10. 1093/ehjci/jeu167.

75. Puntmann VO, D'Cruz D, Smith Z, Pastor A, Choong P, Voigt T, et al. Native myocardial T1 mapping by cardiovascular magnetic resonance imaging in subclinical cardiomyopathy in patients with systemic lupus erythematosus. Circ Cardiovasc Imaging. 2013;6: 295-301. https://doi.org/10.1161/CIRCIMAGING.112.000151.

76. Bohnen S, Radunski UK, Lund GK, Kandolf R, Stehning C, Schnackenburg B, et al. Performance of T1 and T2 mapping cardiovascular magnetic resonance to detect active myocarditis in patients with recent-onset heart failure. Circ Cardiovasc Imaging. 2015;8:e003073. https://doi.org/10.1161/CIRCIMAGING.114. 003073.

77. Radunski UK, Lund GK, Stehning C, Schnackenburg B, Bohnen S, Adam G, et al. CMR in patients with severe myocarditis. JACC Cardiovasc Imaging. 2014;7:667-75. https://doi.org/10.1016/j. jemg.2014.02.005.

78. Sado DM, Kozor R, Corr L, Moon JC. Global myocardial edema in antisynthetase syndrome detected by cardiovascular magnetic resonance mapping techniques. Circulation. 2016;133:e25-6. https:// doi.org/10.1161/CIRCULATIONAHA.115.017430.

79. Ertel A, Pratt D, Kellman P, Leung S, Bandettini P, Long LM, et al. Increased myocardial extracellular volume in active idiopathic systemic capillary leak syndrome. J Cardiovasc Magn Reson. 2015;17: 76. https://doi.org/10.1186/s12968-015-0181-6. 
80. Miller CA, Naish JH, Shaw SM, Yonan N, Williams SG, Clark D, et al. Multiparametric cardiovascular magnetic resonance surveillance of acute cardiac allograft rejection and characterisation of transplantation-associated myocardial injury: a pilot study. J Cardiovasc Magn Reson. 2014;16:52. https://doi.org/10.1186/ s12968-014-0052-6.

81. Banypersad SM, Fontana M, Maestrini V, Sado DM, Captur G, Petrie A, et al. T1 mapping and survival in systemic light-chain amyloidosis. Eur Heart J. 2015;36:244-51. https://doi.org/10. 1093/eurheartj/ehu444.

82. Fontana M, Banypersad SM, Treibel TA, Maestrini V, Sado D, White SK, et al. AL and ATTR cardiac amyloid are different: native T1 mapping and ECV detect different biology. J Cardiovasc Magn Reson. 2014;16:P341. https://doi.org/10.1186/1532-429X-16-S1P341.

83. Thompson RB, Chow K, Khan A, Chan A, Shanks M, Paterson I, et al. T1 mapping with cardiovascular MRI is highly sensitive for Fabry disease independent of hypertrophy and sex. Circ Cardiovasc Imaging. 2013;6:637-45. https://doi.org/10.1161/ CIRCIMAGING.113.000482.

84. Edwards NC, Moody WE, Yuan M, Hayer MK, Ferro CJ, Townend $\mathrm{JN}$, et al. Diffuse interstitial fibrosis and myocardial dysfunction in early chronic kidney disease. Am J Cardiol. 2015;115:1311-7. https://doi.org/10.1016/j.amjcard.2015.02.015.

85. Tham EB, Haykowsky MJ, Chow K, Spavor M, Kaneko S, Khoo NS, et al. Diffuse myocardial fibrosis by T1-mapping in children with subclinical anthracycline cardiotoxicity: relationship to exercise capacity, cumulative dose and remodeling. J Cardiovasc Magn Reson. 2013;15:48. https://doi.org/10.1186/1532-429X-15-48.

86. Ugander, M; 17th Annual SCMR Scientific Sessions [conference presentation]. New Orleans, LA, USA; January 16-19, 2014.

87. Captur G, Manisty C, Moon JC, Cardiac MRI. Evaluation of myocardial disease. Heart. 2016;102(18):1429-35. https://doi.org/10. 1136/heartjnl-2015-309077. 